\title{
Identification of Cross-Country Similarities and Differences in Regulation of Religion Between 2000 and 2014 with Help of Cluster Analysis*
}

\author{
Felix Ettensperger (D) and Elina Schleutker (iD) \\ Department of Political Science, University of Freiburg, Werthmannstr. 12, DE-79085 Freiburg, Germany \\ Corresponding author: Elina Schleutker, E-mail: elina.schleutker@politik.uni-freiburg.de
}

\begin{abstract}
Building on previous quantitative and qualitative research on cross-country differences and similarities in regulation of religion, this paper employs data for 2000 and 2014 from the third round of the Religion and the State project and uses various cluster analysis techniques to identify country clusters based on the form in which countries regulate religion. The analysis separates between democratic and authoritarian countries. We further study if and how the clustering of the countries changes depending on the employed indicators and the employed cut-off points in defining democracy and autocracy. Overall, the results demonstrate the potential and limits of empirical classifications. In addition to the methodological and descriptive contribution, the results are compared and contrasted with previous work on state-religion relationships.
\end{abstract}

\section{Introduction}

Given that governments legislate and enforce regulation of religion, such regulation is an interesting object for the comparative study of public policies. Indeed, regulatory frameworks create opportunity structures, which shape the behavior of religious and religio-political actors (e.g., Soper and Fetzer 2007; Knill and Preidel 2015; Grzymala-Busse 2016). Moreover, current levels of regulation are often a target of political contestation (for the Danish cartoon controversy, see Lindekilde et al. 2009; for religious buildings, see Green 2010; for blasphemy laws, see Stensvold 2020), for example, as majority and minority religious actors often have different preferences regarding regulation (e.g., Gill 1998, 2007). Finally, regulation also influences, directly or indirectly, the everyday life of the citizens (for religiosity, see Stark and Iannaccone 1994; for the operating of the majority religious groups, see

\footnotetext{
${ }^{\star}$ We would like to thank Luca Ozzano and Fabio Bolzonar and the participants of the ECPR 2020 panel "New Perspectives on Religion and Politics (2)" for their helpful suggestions and comments on an early draft of this paper. In addition, we would like to thank the two anonymous reviewers for their suggestions, which were very useful in improving the manuscript.

(c) The Author(s), 2022. Published by Cambridge University Press on behalf of Religion and Politics Section of the American Political Science Association. This is an Open Access article, distributed under the terms of the Creative Commons Attribution licence (http://creativecommons.org/licenses/by/4.0/), which permits unrestricted re-use, distribution and reproduction, provided the original article is properly cited.
} 
Sarkissian 2015, Ch. 3 and Philpott 2019, Ch. 3 and 4). Sometimes regulation also has an impact on human rights, as is the case when it comes to minority religion discrimination and persecution (Philpott and Shah 2018; Fox 2020) and discrimination against non-religious individuals and groups (Humanists International 2020). Due to the importance of regulation of religion, it is thus essential to better understand cross-country patterns in such regulation over time.

While there already are several descriptive comparative investigations about cross-country differences in regulation of religion (e.g. Fox 2008); changes in regulation over time (e.g. Brown 2019); determinants of regulation (e.g. Fox 2006; Buckley and Mantilla 2013); and consequences of regulation for other policy areas such as women's rights (Ben-Nun Bloom 2015), the number of classificatory studies is still somewhat limited. This paper builds on the previous quantitative and qualitative classifications of state-religion relationships and provides a comprehensive classification of both democratic and authoritarian countries in 2000 and 2014 when it comes to regulation of religion. In addition, we briefly comment on the classification with adjusted cut-off points and three categories of regime types. For the purposes of the classification, we make use of the data from the third round of the Religion and State dataset (Fox 2019) and employ hierarchical cluster analysis to identify clusters of countries based on the regulation that is imposed on religion. Moreover, we study if and how the clustering of the countries changes depending on the variables, which are included in the cluster analysis and on the cut-off points, which define democracy and autocracy. A particular emphasis is given to a discussion regarding the similarities and differences between our classifications and previous work on state-religion relationships in autocratic (Sarkissian 2015; Fox 2019; Philpott 2019; Schleutker 2021) and democratic (Kuru 2007; Madeley 2009; Driessen 2014; Buckley 2017; Soper and Fetzer 2018; Fox 2019) countries. In addition, we discuss how our results can be utilized in future research on religion and politics.

The paper is structured as follows: In section 2, we review the previous research in the field of regulation of religion and discuss the importance of classifications. Our methodology is explained in section 3, followed by the presentation of the results for authoritarian (section 4) and democratic (section 5) countries, and the contrasting of these results with the previous research on the topic. Section 6 concludes.

\section{Comparative Politics and Regulation of Religion}

To start with a definition, regulation of religion can be understood as a multidimensional concept. In particular, it is common to distinguish between, on the one hand, government regulation of religion and, on the other hand, social regulation of religion (i.e., regulation imposed on religious groups or individuals by non-governmental actors). As for the government regulation, it is further customary to distinguish between two different dimensions, namely positive endorsement of and negative restrictions on religion. The positive endorsement of religion comprises the positive actions of the government toward religion (e.g., financial support, institutional inclusion). In contrast, negative restrictions on religion are government policies, which restrict the freedom of religion (e.g., restrictions on religious institutions, restrictions 
on the practice of religion) (for discussion, see Grim and Finke 2006; Gill 2007, 12ff). These different aspects of regulation are further conceptualized (and consequently operationalized) slightly differently in the different datasets on regulation (Grim and Finke 2006; Brown 2019; Fox 2019; Pew Research Center 2019).

\section{What Do We Know About Regulation of Religion?}

In descriptive studies, some scholars have investigated whether the decline of religion predicted by the secularization theory (for a review, see Gorski and Altinordu 2008; Fox 2013, 17-35) has taken place. While the long-term trend has indeed been a decline over the past two centuries (Brown 2019), there are indications that since the 1990s the regulation of religion has increased (Fox 2006, 2014). Further, some of the descriptive studies focus on regulation in particular geopolitical contexts (Fox 2008, 2013, 2020; Sarkissian 2009) or aim to provide an annual report about global trends (Pew Research Center's reports since 2009).

In addition, several studies focus on the determinants of regulation. The selection of independent variables in these studies is often based on theoretical considerations related to, for example, the secularization/modernization theory; the theory about the clash of civilizations (Huntington 1993); the rational choice theory about religion (Stark and Iannaccone 1994; Gill 1998, 2007); and some general considerations about political institutions and the influence of one regulatory policy on another one (e.g., Grim and Finke 2007; Fox et al. 2019).

To review the findings, the results regarding the relationship between regulation and $\mathrm{GDP} /$ capita are inconsistent and some studies even show that regulation tends to be higher in countries with higher GDP/capita. This is in contrast to the secularization/ modernization theory, but in accordance with the idea that increases in state capacity are related to higher levels of regulation (for discussion, see Buckley and Mantilla 2013). Further, there is some indication that regulation correlates with majority religion affiliation, which seems to give some support for Huntingtonian ideas about the importance of civilizations. For example, Muslim majority countries have higher levels of regulation than Christian majority countries (e.g., Fox 2006). As for the religious demography, several studies support the idea that religious fragmentation decreases regulation of religion (e.g., Buckley and Mantilla 2013), whereas religious homogeneity increases regulation (e.g., Fox 2006). Finally, concerning political institutions, we know that regulation is lower in democratic countries (e.g., Fox 2006; Schleutker 2019) and that experiences with communism increase negative restrictions on religion (e.g. Finke and Martin 2014; Mataic 2018). Finally, judicial independence seems to have a dampening impact on regulation (e.g., Finke and Martin 2014; Finke et al. 2017).

In comparison to the high number of descriptive and explanatory studies on regulation, the number of classificatory studies is low. As for the quantitatively oriented studies (see Table 1), previous classifications vary when it comes to the employed data; method; included number of countries and conclusions regarding the classificatory categories. As for the qualitatively oriented studies (see Table 2), the conceptualizations focus on understanding how the political ideology of the state in terms of the different types of nationalisms and secularisms influence the relationship between religion and the state. These previous studies are helpful in identifying the most important 
Table 1. Selected quantitatively oriented classifications on state-religion relations

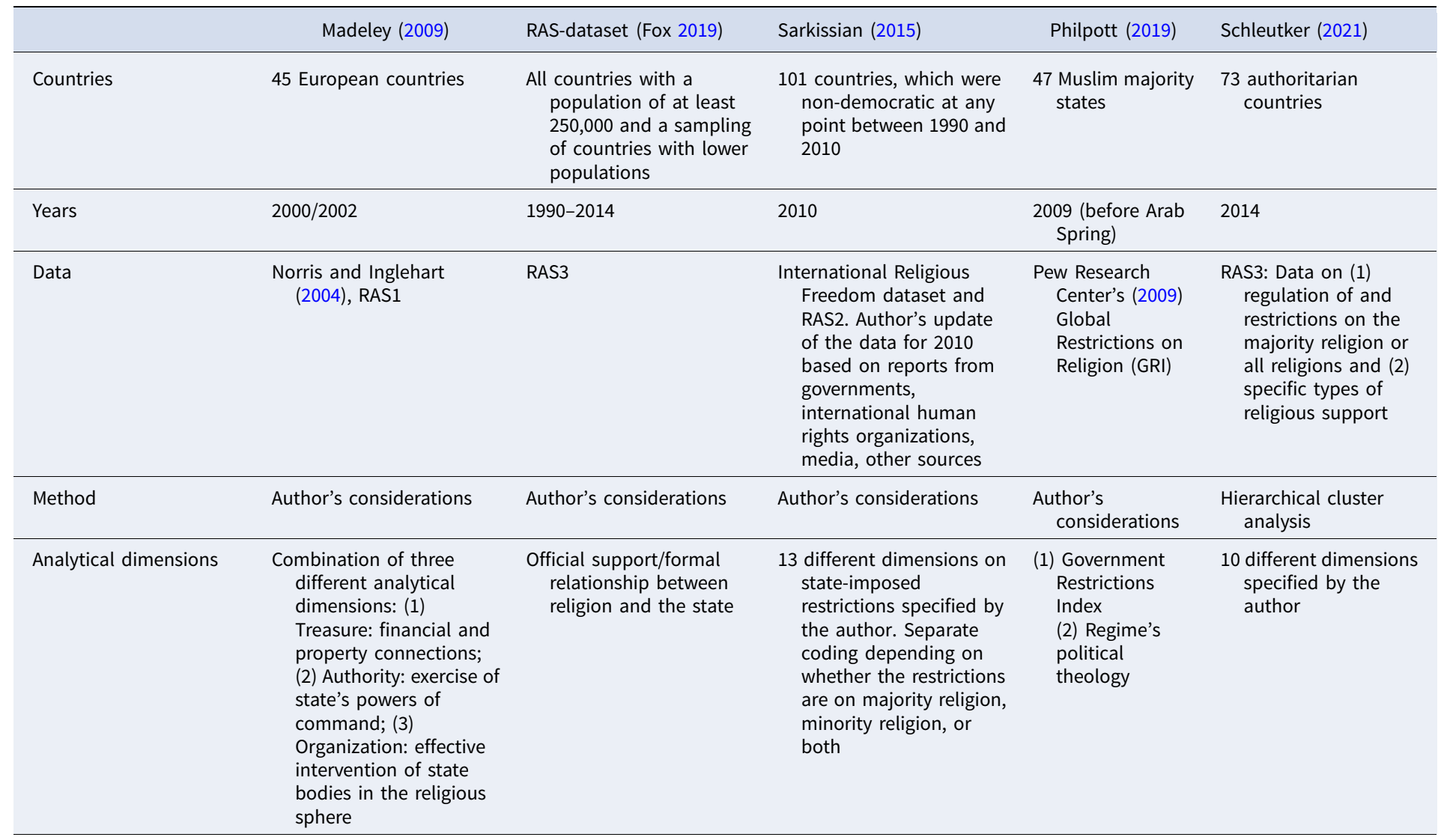


Table 1. (Continued.)

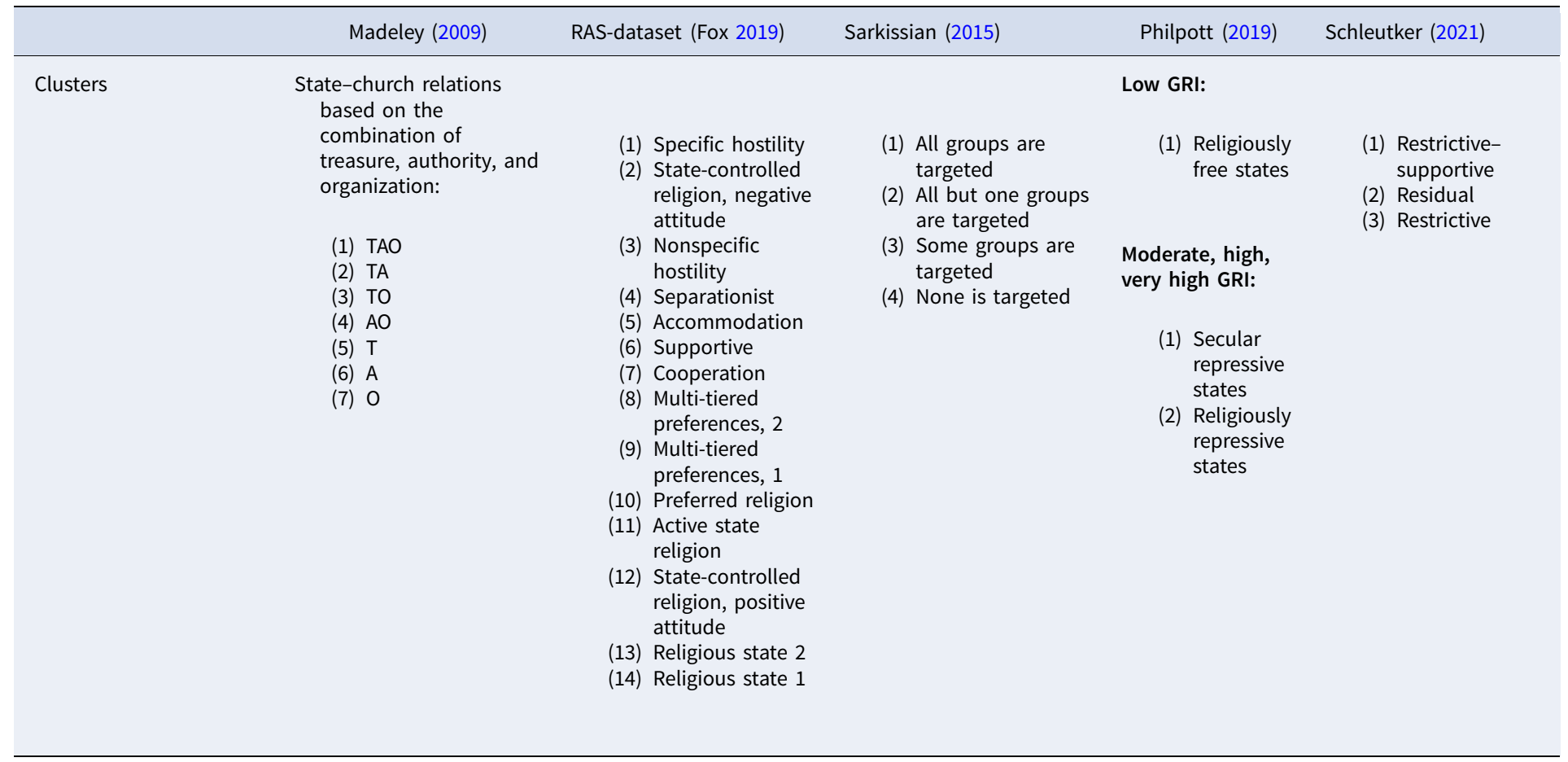


Table 2. Selected qualitative conceptualizations of state-religion relationships

\begin{tabular}{|c|c|c|c|c|}
\hline & Kuru (2007) & Driessen (2014) & Buckley (2017) & Soper and Fetzer (2018) \\
\hline Main idea & $\begin{array}{l}\text { There are differences in } \\
\text { the way in which } \\
\text { secular states behave } \\
\text { vis-a-vis religion }\end{array}$ & $\begin{array}{l}\text { Democratic countries can } \\
\text { respect the twin tolerations } \\
\text { and still be religiously } \\
\text { friendly }\end{array}$ & $\begin{array}{l}\text { Benevolent secularism defined as a } \\
\text { distinct form of secularism in } \\
\text { comparison to Kuru's passive } \\
\text { and assertive secularism. } \\
\text { Benevolent secularism is } \\
\text { characterized by (1) } \\
\text { differentiation, (2) cooperation, } \\
\text { and (3) principled distance in the } \\
\text { relationships between the state } \\
\text { and secular actors }\end{array}$ & $\begin{array}{l}\text { There are differences in the way in } \\
\text { which secularism and } \\
\text { nationalism interact. Depending } \\
\text { on these interactions, it is } \\
\text { possible to distinguish three } \\
\text { different types of religion- } \\
\text { nationalism models }\end{array}$ \\
\hline \multicolumn{5}{|l|}{ Groups } \\
\hline 1 & $\begin{array}{l}\text { Passive secularism: state } \\
\text { has a passive role } \\
\text { regarding religion. } \\
\text { Countries: United States }\end{array}$ & $\begin{array}{l}\text { Religiously friendly } \\
\text { democracy: a democracy, } \\
\text { where the levels of religious } \\
\text { favoritism are relatively } \\
\text { high, and levels of religious } \\
\text { regulation relatively low }\end{array}$ & $\begin{array}{l}\text { Benevolent secularism Countries: } \\
\text { Ireland, Senegal, Philippines }\end{array}$ & $\begin{array}{l}\text { Secular nationalism: contested } \\
\text { relationship between religion } \\
\text { and the nationalist project. } \\
\text { Separation of religion-state } \\
\text { institutional links. Countries: } \\
\text { Uruguay (stable), India (unstable) }\end{array}$ \\
\hline 2 & $\begin{array}{l}\text { Assertive secularism: state } \\
\text { actively excludes } \\
\text { religion from the public } \\
\text { sphere to force it to the } \\
\text { private sphere. } \\
\text { Countries: France, } \\
\text { Turkey }\end{array}$ & $\begin{array}{l}\text { Other democracies: low levels } \\
\text { of both government } \\
\text { favoritism and government } \\
\text { regulation of religion }\end{array}$ & & $\begin{array}{l}\text { Religious nationalism: consensual } \\
\text { relationship between a } \\
\text { particular religious group and } \\
\text { the nationalist project. Multiple } \\
\text { religion-state contacts (to a } \\
\text { particular group). Countries: } \\
\text { Greece (stable), Malaysia } \\
\text { (unstable) }\end{array}$ \\
\hline 3 & & & & $\begin{array}{l}\text { Civil-religious nationalism: } \\
\text { consensual relationship between } \\
\text { multiple religious traditions and } \\
\text { the nationalist project. Benign } \\
\text { separation or pluralistic } \\
\text { accommodation. Countries: } \\
\text { United States (stable), Israel } \\
\text { (unstable) }\end{array}$ \\
\hline
\end{tabular}


analytical dimensions regarding the state-religion relationships; providing a classification of the countries in one point of time (quantitative studies); investigating the interaction between religion and state in detail (qualitative studies) and often also providing discussion and evidence regarding the determinants of state-religion relationships.

\section{Classification and Regulation of Religion}

The current study builds on the work listed in Tables 1 and 2 by employing numerical methods to investigate how the countries cluster. Such methods provide a relatively time-efficient way of classifying countries and, moreover, they are flexible in that it is usually unproblematic to include and exclude variables in order to study if and how the classification of the countries changes as a consequence. This can be contrasted with classifications, which are based on theoretical considerations and are hence time-intensive to construct. Indeed, when the classification is based on theoretical considerations, it is impossible for one author to discuss if and how the classification of countries would change, in case a different set of theoretical dimensions would be selected as a starting point. As a consequence, as is evidenced by the studies on welfare state regimes (for a review, see Arts and Gelissen 2002), it takes the cumulative work of several researchers to produce competing classifications, which finally can be compared regarding their similarities and differences and employed to identify outliers which are situated between distinguished groups of countries.

Thus, in contrast to the previous quantitatively based classifications on regulation of religion, which focus on a particular geopolitical region, year, method, and indicators, the methods we apply in this paper make it possible to classify a large set of countries. Moreover, we are able to study how the classification changes when the same method is consistently employed, but when a different set of indicators is included. In addition, we are able to identify borderline cases between the clusters and assess if and how the classification of the countries changes over time. By further comparing our results with the previous large $\mathrm{N}$-studies listed in Table 1, we are able to discuss if and how the classification of the countries changes when the variable selection is conducted based on different analytical dimensions. Such comparison enhances our understanding of the robustness of the country clusters. Moreover, by comparing our results with the qualitative studies listed in Table 2, we can discuss if our findings are compatible with the theoretical dimensions outlined in these studies and thus provide some preliminary conclusions as to whether the findings and theoretical frameworks from qualitative case studies may be generalizable to a larger set of countries.

\section{Methodology}

\section{Methods}

The methods applied in this study are hierarchical clustering including detailed analysis of the best cluster number and silhouette structure. The hierarchical clustering is conducted with the R package "FactoMineR" (Le et al. 2008) and the package "factoextra" (Kassambara and Mundt 2017). For determining the best number of clusters, we employed the package NbClust (Charrad et al. 2014). The data, code, and full result reports are available for potential replication in the online repository. 
Applying these methods, we draw inspiration from the increasing number of studies in the field of public policy, which have successfully employed cluster analysis techniques to classify countries (e.g., Obinger and Wagschal 2001; Duit 2016; Kattler and Ettensperger 2020). We find cluster analysis particularly suited for our study, as it enables the classification of a large number of countries and further makes it possible to study if and how the clustering of the countries changes over time and when a different set of indicators is used. Thus, a comparison of the results from various cluster analyses makes it possible to detect robust cluster patterns within the data, find out which countries change cluster affinity over time and identify both outliers as well as borderline cases between two clusters.

The clustering is visualized in a dendrogram, showing us the closeness and relationship between country-cases in our sample. The closer the cases are connected via the branches of the tree diagram, the higher the similarities between these individual cases are. This allows us to compare our results not only to quantitative, but also to qualitative studies in the domain of regulation of religion. We can evaluate if previous observations about the similarities and differences in state-religion relationships are reflected in the empirical data by evaluating the distance of cases within clusters. If we find that countries, despite their common doctrine or historical background arrive at very different patterns of regulation, and are thus located in distant branches, this provides valuable insights and potential for further research.

Regarding the cluster analysis, the first step of the empirical investigations was to study what the mathematically best number of clusters is. This is important, as the identification of the mathematically optimal number of clusters will minimize the number of countries with low cluster affinity. The applied number of clusters is based on the mathematically recommended number of clusters suggested applying the majority-rule to the results from 26 index algorithms included in the package NbClust. Once the mathematically optimal number of clusters is determined, hierarchical cluster analysis (Ward's method, ward.D2 in R, with the Euclidean distance) was conducted by enforcing the optimally best number of clusters as a solution. In the agglomerative hierarchical clustering that we employ, the clustering is conducted bottom-up: In the beginning, each observation is treated as a separate cluster. In the process of clustering, similar clusters are then merged together (for details, see Everitt et al. 2011, Ch. 4). The results from each cluster analysis are shown in dendrogram format, which makes it possible to study how the cluster trees are generated, and how the internal structure, the existence of sub-clusters, and the proximity of cases inside of clusters are constituted.

To study the quality of the formed clusters, we employ silhouette analysis (see Rousseeuw 1987). The silhouette width of an individual country can vary between -1 and 1 . Values close to 1 indicate a good fit (the country is very similar to the other countries in the cluster), whereas values close to -1 indicate a poor fit (the country is very dissimilar from the other countries in the cluster). In particular, negative silhouette width for individual countries suggests that these countries may be assigned to a cluster that does not share a majority of attributes with them, and another cluster is almost equally good to describe them. Finally, the average silhouette width for a cluster tells us about the quality of the clustering structure. In case the average silhouette width is above 0.5 , the cluster structure is stable, whereas an average 
width below 0.2 suggests a lack of a substantial clustering structure (Everitt et al. 2011, 129).

\section{Data}

The measurement of regulation of religion is based on the third round of the Religion and State project, RAS3 (Fox 2019). The RAS3 dataset includes altogether 36 variables on discrimination against minority religions; 29 types of restrictions on the regulation of and restrictions on the majority religion and all religions and 27 types of non-government discrimination, harassment, acts of prejudice and violence against minority religions. All these variables are coded from 0 to 3 . The total level of regulation in each dimension is the sum of the variables in the category $(108,87$, and 81 respectively). In addition, there are 52 binary-coded variables on the specific types of religious support, which can be combined into an additive composite index.

Results from numerical classification always depend on the method of classification and the indicators, which are included in the analysis. Consequently, we find it important to study to what extent the countries cluster differently depending on the kind of indicators that are included in the cluster analysis. In case the countries form clusters rather similarly for different indicator selections, we can be confident in the robustness of the identified clusters. If we find dissimilar clusters with different variable selections, this indicates that cases within the cluster results are only partially aligned by subsets of the investigated properties. Finally, the classification of countries based on different sets of indicators can inform us about outliers and borderline cases.

Based on the above considerations, we decided to perform three types of cluster analysis (see Table 3 for an overview). The first type includes the four composite variables on the total level of regulation ("four-variable clustering"). The second type focuses on government regulation ("three-variable clustering"). In the third type, the government regulatory practices are separated into 15 categories following the RAS3 data structure. This clustering thus considers the qualitatively different types of government regulatory practices separately ("15-variable clustering”).

\section{Case Selection}

The RAS3 dataset includes information for 183 countries. As we are interested in the regulation of religion in independent countries only, we excluded seven states (Cyprus/Turkish, Gaza, Kosovo, Kurdistan, Palestinian Authority/West Bank, Taiwan, Western Sahara, and Zanzibar) which were not member states of the United Nations (see UN 2020). Regarding the classification of countries, we find it important to separate between autocracies and democracies for three reasons. Firstly, the process of formulating the laws regarding religion is different (competitive and open versus non-competitive and closed). Secondly, there are considerable differences when it comes to the consequences of not following the rules (including the range of punishment) as well as the means, which are employed to coerce citizens into following the rules (rule of law and independent judiciary versus arbitrary and often excessive punishment and non-independent judiciaries). Thirdly, democratic and authoritarian countries may differ greatly when it comes to the capacity of the 
Table 3. List of variables included in the three cluster analysis

\begin{tabular}{|c|c|c|c|}
\hline Clustering & $\begin{array}{l}\text { Number of } \\
\text { variables }\end{array}$ & Variables & Abbreviation in the dataset \\
\hline Total regulation & 4 & $\begin{array}{l}\text { Religious discrimination against minority religions } \\
\text { Regulation of and restrictions on the majority religion or all } \\
\text { religions } \\
\text { Specific types of religious support } \\
\text { Discrimination, harassment, acts of prejudice and violence } \\
\text { against minorities }\end{array}$ & $\begin{array}{l}\text { MXX2014X } \\
\text { NXX2014X } \\
\text { LXX2014X } \\
\text { WSOCDISX2014X }\end{array}$ \\
\hline Government regulation & 3 & $\begin{array}{l}\text { Religious discrimination against minority religions } \\
\text { Regulation of and restrictions on the majority religion or all } \\
\text { religions } \\
\text { Specific types of religious support }\end{array}$ & $\begin{array}{l}\text { MXX2014X } \\
\text { NXX2014X } \\
\text { LXX2014X }\end{array}$ \\
\hline $\begin{array}{l}\text { Specific type of government } \\
\text { regulation }\end{array}$ & 15 & $\begin{array}{l}\text { Restrictions on religious practices } \\
\text { Restrictions on religious institutions and the clergy } \\
\text { Restrictions on conversion and proselytizing } \\
\text { Other restrictions } \\
\text { Restrictions on religion's political role } \\
\text { Restrictions on religious institutions } \\
\text { Restrictions on religious practices } \\
\text { Other regulation of religion } \\
\text { Laws on relationships, sex, and reproduction } \\
\text { Laws restricting women } \\
\text { Other laws legislating religious precepts } \\
\text { Institutions or laws which enforce religion } \\
\text { Funding religion } \\
\text { Entanglement of government and religious institutions } \\
\text { Other forms of support for religion }\end{array}$ & $\begin{array}{l}M X 01 X 2014 X-M X 12 X 2014 X \\
M X 13 X 2014 X-M X 20 X 2014 X \\
M X 21 X 2014 X-M X 27 X 2014 X \\
M X 28 X 2014 X-M X 36 X 2014 X \\
\text { NX01X2014X-NX05X2014X } \\
\text { NX06X2014X-NX14X2014X } \\
\text { NX15X2014X-NX21X2014X } \\
\text { NX22X2014X-NX29X2014X } \\
\text { LX01X2014X-LX07X2014X } \\
\text { LX08X2014X-LX11X2014X } \\
\text { LX12X2014X-LX21X2014X } \\
\text { LX22X2014X-LX26X2014X } \\
\text { LX27X2014X-LX37X2014X } \\
\text { LX38X2014X-LX43X2014X } \\
\text { LX44X2014X-LX52X2014X }\end{array}$ \\
\hline
\end{tabular}


government to impose the different rules and regulations (non-fragile and fragile states).

To separate between democratic and autocratic countries, data from V-Dem's Version 10 Polyarchy Index (Coppedge et al. 2020) was employed. The Polyarchy Index is based on Dahl's (1989) definition of polyarchy and relies on expert ratings. The various dimensions of polyarchy are measured with several indicators, which then are aggregated to the Polyarchy Index (for details, see Teorell et al. 2019). The Index can take on values between 0 (not democratic) to 1 (fully democratic). To separate democratic and authoritarian countries from each other, we used the cutoff point 0.5 (countries for which the Polyarchy Index is lower than 0.5 are defined as authoritarian). This criterion is loosely based on Lührmann et al. (2018, 63f), who use the same cut-off point, but who in addition require the democratic countries to take on certain values in two indexes, namely "multiparty elections" and "free and fair elections." To keep it simple, we did not rely on data from additional indexes, but conducted different clustering versions using higher thresholds in polyarchy for the democracy and autocracy categories to compare them with our main results (see the discussion below). Altogether five countries (Andorra, Bahamas, Belize, Brunei, and Liechtenstein) had to be excluded due to missing V-Dem data. Thus, the analysis includes 167 countries in year 2000 (85 democratic countries; 82 autocratic countries), and 170 countries in year 2014 (93 democratic countries; 77 autocratic countries). The difference between the number of included countries between the years is explained by the fact that Montenegro, South Sudan, and Timor became independent after 2000.

While we maintain that it is important to separate between democratic and authoritarian countries, we are aware of the arguments, which caution against binary categories and urge researchers to at least separate between "a middle category" of anocracies (for discussion, see Elkins 2000). Thus, while our main analysis is focused on democratic and authoritarian countries, we also briefly comment on how the classification would change in case we would separate between three categories of countries. In order to divide the countries into three groups, we use the following cut-off points: Countries below the threshold of 0.3 are classified as autocracies and countries above the threshold of 0.7 are classified as democracies. The remaining countries are understood as anocracies.

\section{Observation Period}

To understand if and to what extent the detected classifications have remained stable over time, the clustering was performed for two years, 2000 and 2014 (for 2014 we use data with the suffix "2014X" in the RAS3 dataset). The year 2014 is selected, as it is the latest available data from the RAS3. The decision to focus on year 2000 instead of the year for the earliest available data (1990) requires some further clarification. Most importantly, it is reasonable to argue that many of the post-communist countries took several years to develop and establish their democratic or autocratic institutions, as well as regulatory policies regarding religion. We do not wish to study regulatory policies in transition and hence selected the year 2000 as a starting point, given that the most turbulent transitional period for a large majority of the 
Table 4. Number of indices, which support a solution with $0-10$ clusters, authoritarian countries

\begin{tabular}{|c|c|c|c|c|c|c|c|c|c|c|c|}
\hline & 0 & 1 & 2 & 3 & 4 & 5 & 6 & 7 & 8 & 9 & 10 \\
\hline \multicolumn{12}{|l|}{2000} \\
\hline $\begin{array}{l}\text { 4-variable } \\
\text { clustering }\end{array}$ & 2 & 1 & 5 & 5 & 0 & 4 & 1 & 0 & 0 & 3 & 5 \\
\hline $\begin{array}{l}\text { 3-variable } \\
\text { clustering }\end{array}$ & 2 & 1 & 7 & 8 & 0 & 1 & 0 & 1 & 1 & 3 & 2 \\
\hline $\begin{array}{l}\text { 15-variable } \\
\text { clustering }\end{array}$ & 2 & 1 & 2 & 15 & 1 & 1 & 0 & 0 & 0 & 1 & 3 \\
\hline \multicolumn{12}{|l|}{2014} \\
\hline $\begin{array}{l}\text { 4-variable } \\
\text { clustering }\end{array}$ & 2 & 1 & 6 & 6 & 5 & 0 & 1 & 0 & 1 & 1 & 3 \\
\hline $\begin{array}{l}\text { 3-variable } \\
\text { clustering }\end{array}$ & 2 & 1 & 5 & 8 & 0 & 4 & 5 & 0 & 0 & 0 & 1 \\
\hline $\begin{array}{l}\text { 15-variable } \\
\text { clustering }\end{array}$ & 2 & 1 & 1 & 18 & 0 & 0 & 1 & 1 & 0 & 0 & 1 \\
\hline
\end{tabular}

post-communist countries can be assumed to have been over by then. Selection of year 2000 as a starting point also ensures that the impact of certain conflicts (e.g., Yugoslav wars) and the following transitional periods is minimized. As the war on terror may have influenced the regulation of religion, it is important to start the study before 9/11. Thus, 2000 appears as a reasonable, even though a somewhat arbitrary compromise between the various considerations.

The discussion below is focused on the results for 2014, as well as on the changes between 2000 and 2014. The detailed results for year 2000, as well as the results regarding the different cut-off points for democracy, anocracy, and autocracy can be found in the online Appendix.

\section{Results for Authoritarian Regimes}

As presented in Tables 4 and 5, regarding the three-variable and 15-variable clustering, the majority of the indices in NbClust suggest that three is the optimal number of clusters when regulation of religion is studied. For the four-variable clustering, the results from NbClust are inconclusive: In 2000, five indices suggested that two, three, and 10 are the optimal number of clusters, whereas in 2014, six indices suggested that two and three are the optimal number of clusters. To increase the comparability of the results, the decision was made to enforce the countries into three clusters even in the four-variable clustering.

When the countries are enforced into three clusters, the results for 2000 show that many countries cluster differently when the number of variables that is included in the cluster analysis varies. In 2014, however, the clustering of the authoritarian countries is relatively stable independently from the number and type of the included variables (only four countries, namely Mauritania, Sri Lanka, Somalia, and Thailand switch back and forth between the clusters). Thus, it appears that by 2014, a 
Table 5. Average cluster silhouette widths and number of countries in each cluster, authoritarian countries

\begin{tabular}{cccc}
\hline & Cluster 1 & Cluster 2 & Cluster 3 \\
\hline 2000 & & & \\
\hline 4-variable clustering & $0.03(32)$ & $0.73(38)$ & $0.26(12)$ \\
\hline 3-variable clustering & $0.30(21)$ & $0.54(56)$ & $0.74(5)$ \\
\hline 15-variable clustering & $0.21(22)$ & $0.50(44)$ & $0.14(16)$ \\
\hline 2014 & & & \\
\hline 4-variable clustering & $0.24(19)$ & $0.64(40)$ & $0.25(18)$ \\
\hline 3-variable clustering & $0.30(23)$ & $0.73(36)$ & $0.30(18)$ \\
\hline 15-variable clustering & $0.26(21)$ & $0.51(38)$ & $0.20(18)$ \\
\hline
\end{tabular}

consolidation of the clusters had taken place. Yet, in both 2000 and 2014, we can observe three distinctive clusters, which are different from each other in terms of regulation of religion, and also to a certain extent when it comes to their geographical location, majority religion, and political history. The detailed results for year 2000, including dendrograms, cluster average values of regulation, and countries with negative silhouette widths, can be found in the online Appendix.

\section{Results for 2014}

As for the total level of regulation (four-variable clustering), the results are shown in Figure 1 (dendrogram). Cluster 1 consists of 19 countries mostly located in the MENA region. The average levels of regulation (Figure 2a) in this cluster are high, particularly when it comes to support for religion and social regulation of religion. Further, cluster 2 is the largest cluster (40 countries, mainly located in Sub-Saharan Africa) with low average levels of regulation. Finally, in the third cluster, we find 18 countries from various geographical locations. With the exception of Myanmar, Syria, and Turkey, all countries in this cluster have made experiences with communist rule. The average levels of negative restrictions (regulation and discrimination) in this cluster are high, but the mean levels for support and social regulation are lower. The average silhouette widths show that the largest cluster, cluster 2 , is the most internally coherent one, whereas cluster 1 and cluster 3 have lower internal coherence. Finally, Armenia, Eritrea, and Russia (in cluster 3) have negative silhouette widths and are thus barely part of the cluster. Rather, Armenia and Eritrea may be better described with cluster 2, whereas Russia may rather be described with cluster 1 .

Regarding the government regulation of religion (three-variable clustering), the results (Figures 3 and $2 b$ ) are very similar to the results for the total level of regulation. Indeed, only four countries, namely Mauritania, Sri Lanka, Somalia, and Thailand are in a different cluster when social regulation of religion is excluded from the cluster analysis (in the four-variable clustering, these countries were placed in cluster 2, whereas in the three-variable clustering, these countries are placed in cluster 1). Consequently, the cluster mean values are almost the same as well. 


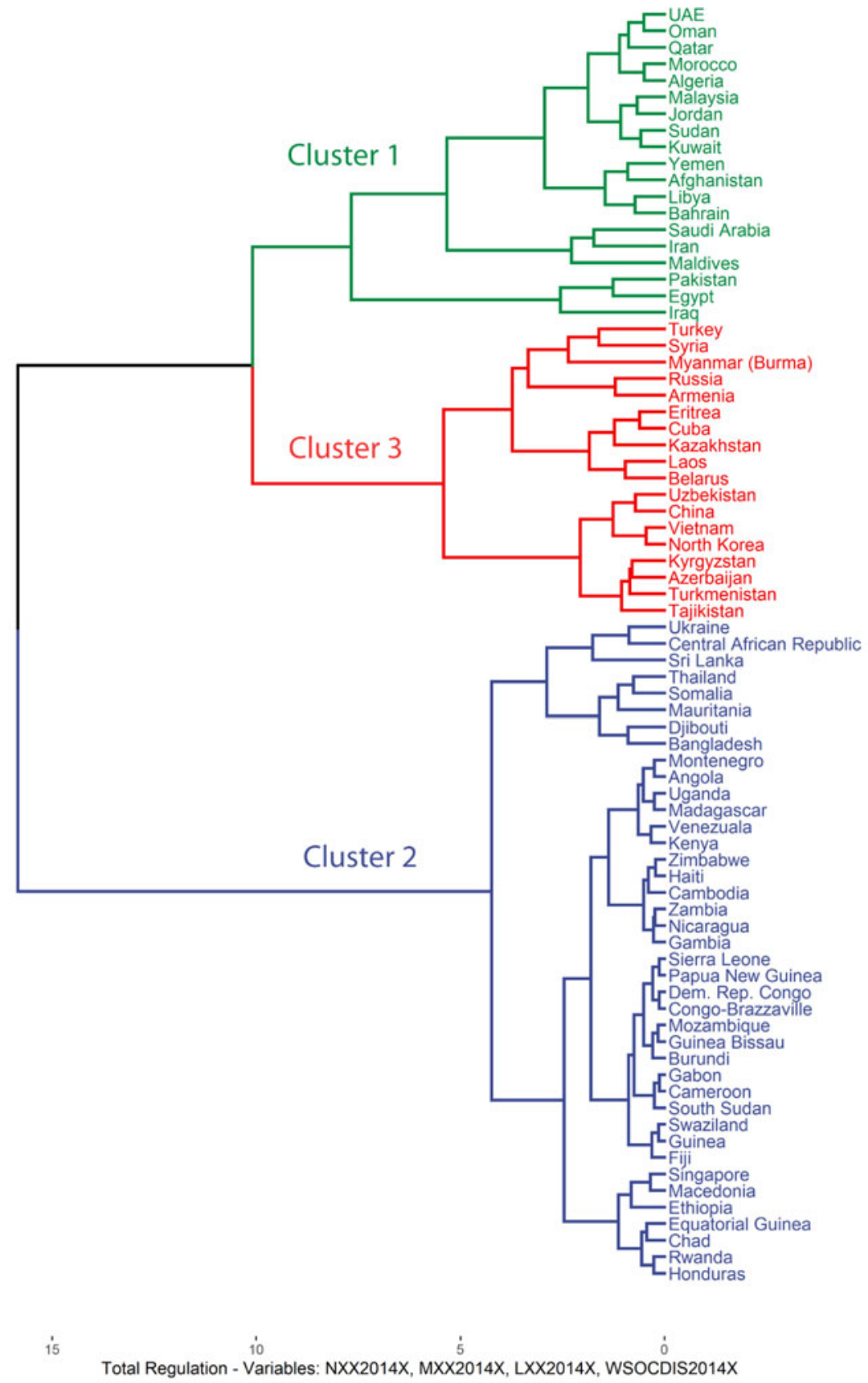

Figure 1. Dendrogram of autocracies-total regulation, 2014 

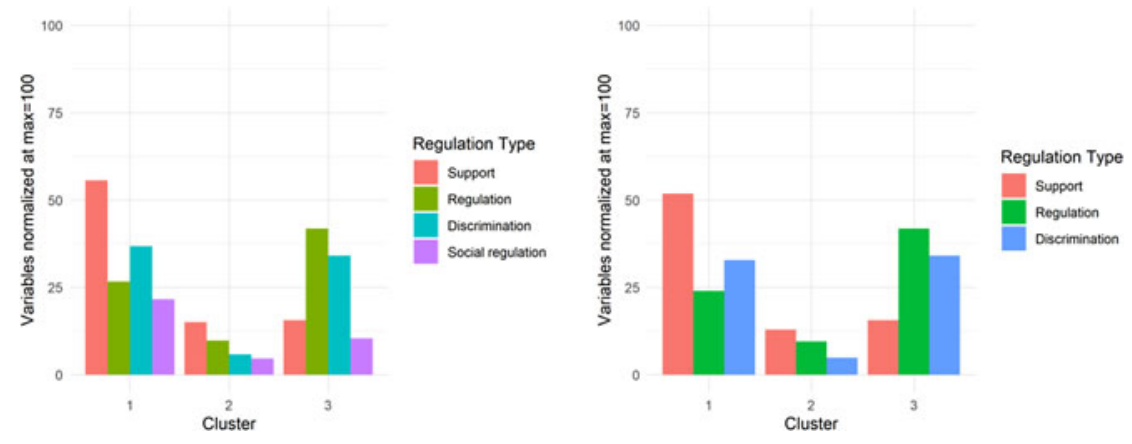

Figure 2. Cluster mean levels of regulation in 2014: total level of regulation and government regulation of religion. (a) Average level of total regulation. (b) Average level of government regulation

Finally, Thailand, Somalia, and Sri Lanka have negative silhouette widths and have thus a strong tendency to cluster into the second cluster. This further gives support to the idea that these countries can be seen as borderline cases between cluster 1 and cluster 2. Further, three countries which are now placed in cluster 3 have negative silhouette widths, which suggests that they have a strong tendency to cluster in cluster 2 (Armenia, Eritrea) or cluster 1 (Syria).

When the countries are clustered based on the 15 categories of specific type of regulation, the clustering of the countries is again very similar (see Appendix Figure A.11). Indeed, in comparison to the four-variable clustering, only Mauritania and Somalia are clustered differently (they are now placed in cluster 1). The average silhouette widths again show that the largest cluster is the most cohesive one, whereas cluster 1 and cluster 3 have a weaker clustering structure. The negative silhouette widths for individual countries suggest that Mauritania and Somalia (cluster 1) have a strong tendency to cluster to cluster 2; that Armenia and Eritrea (cluster 3) have a strong tendency to cluster to cluster 2; and that Syria (cluster 3) has a strong tendency to cluster to cluster 1 .

Some further interesting differences between the clusters emerge when the mean levels of specific types of regulation are observed (Appendix Figure A.12). As for the regulation of majority religion or all religions, the average levels of restrictions on religion's political role and religious institutions, as well as other restrictions on religion are at high levels in cluster 1 and cluster 3 . In cluster 1 , however, religious practices are regulated to a much lower rate than in cluster 3. Moreover, it is of interest that while in the second cluster, the average levels of regulation are in general at low levels, the average levels of restrictions on religion's political role are somewhat higher than the average levels of the other types of restrictions.

Regarding the specific types of support for religion, the mean levels in cluster 1 are high independently from the type of such support. This can be contrasted with clusters 2 and 3, where such support is more selective. Indeed, in cluster 2, the mean levels of laws on relationships, sex, and reproduction are higher than the support for other types. Moreover, funding of religion and other forms of support for religion 


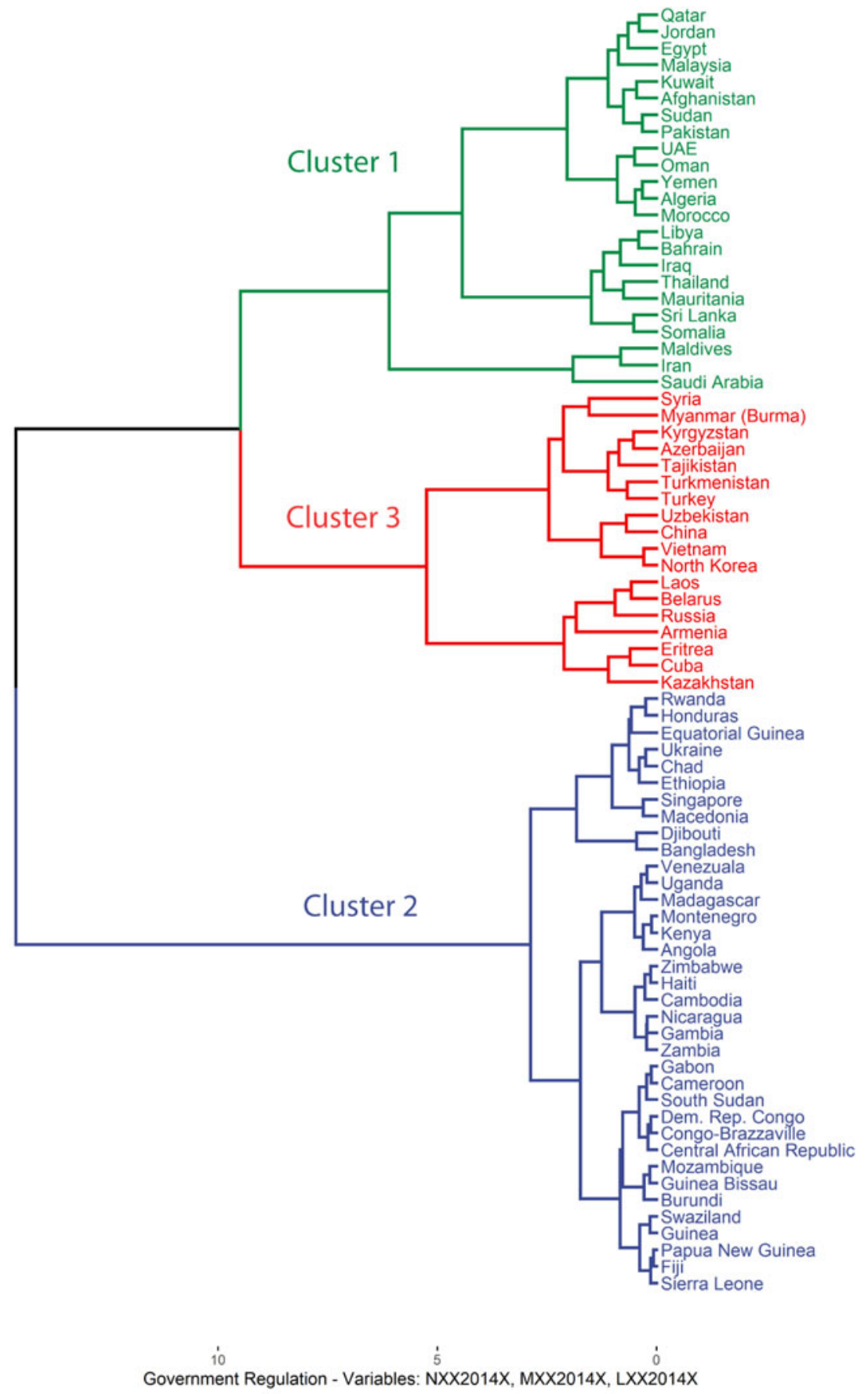

Figure 3. Dendrogram of autocracies-government regulation of religion, 2014 
are likewise at relatively high levels. In cluster 3 , in turn, the mean levels for funding of religion, entanglement of government and religious institutions, and other forms of support for religion are at higher levels.

Finally, as for the discrimination against minority religions, the mean levels are high both in clusters 1 and 3, but lower in cluster 2. The clearest difference between cluster 1 and cluster 3 is that in cluster 3 the mean levels of restrictions on religious institutions and the clergy are higher than the other restrictions, whereas in cluster 1 it is especially restrictions on conversion and proselytizing, which are high.

\section{Comparison Between 2000 and 2014}

As already mentioned above, the clustering of the countries changes somewhat in 2000 depending on the indicators, which are included in the cluster analysis, whereas in 2014 the clustering is almost the same independently from the included indicators. Thus, by 2014 the stabilization of the clustering has taken place. The comparison of the clustering of the countries between years 2000 and 2014 shows that the overall patterns in the clustering between the years are nevertheless relatively similar, and that it is possible to distinguish between three qualitatively different worlds of authoritarian regulation of religion.

The details regarding the countries, which switch between the clusters over time, can be found in Figures 4 and 5. As for the countries, which change between clusters over time when the total level of regulation is studied, Mauritania and Somalia leave cluster 1 and join cluster 2 in 2014 (both countries had negative silhouette widths in 2000 and thus already appeared to be borderline cases between clusters 1 and 2). Further, six countries, namely Armenia, Belarus, Laos, Myanmar, Russia, and Syria, exit cluster 1 to join cluster 3 in 2014. In all of these countries, discrimination against minority religion has increased over time and in most of the countries, regulation against majority religion/all religions has likewise increased. Regarding the countries, which enter and exit cluster 2, Macedonia and Singapore, which in 2000 barely belonged to cluster 3 (i.e., had negative silhouette widths), join cluster 2 by 2014. Further, as already discussed above, Mauritania and Somalia from cluster 1 join cluster 2. As for the countries, which exit cluster 2 between 2000 and 2014, the most notable cases are Eritrea and Kyrgyzstan. In these two countries, both regulation and especially discrimination increase considerably over time and consequently, these countries join cluster 3 in year 2014. As for the countries in cluster 3, as already discussed above, Armenia, Belarus, Laos, Myanmar, Russia, and Syria from cluster 1, as well as Eritrea and Kyrgyzstan from cluster 2 join this cluster by 2014. Further, it is worth highlighting that Turkey, which in 2000 still was democratic, joins this cluster in 2014. Regarding the countries, which exit the cluster, Macedonia and Singapore join cluster 2 and Tunisia, which by 2014 had become democratic, now exits the cluster.

The comparison of the results for 2000 and 2014 from the clustering for government regulation (Figure 6) shows similar robust core groups of countries, even though the details regarding the placement of individual countries vary somewhat.

\section{Comparison to Previous Research}

A comparison of our results to the studies listed in Table 1 shows that in general, our results are similar to previous attempts to cluster authoritarian countries, and 
Change in cluster composition between 2000 and 2014

Autocracies - Total Regulation (4-Variables)

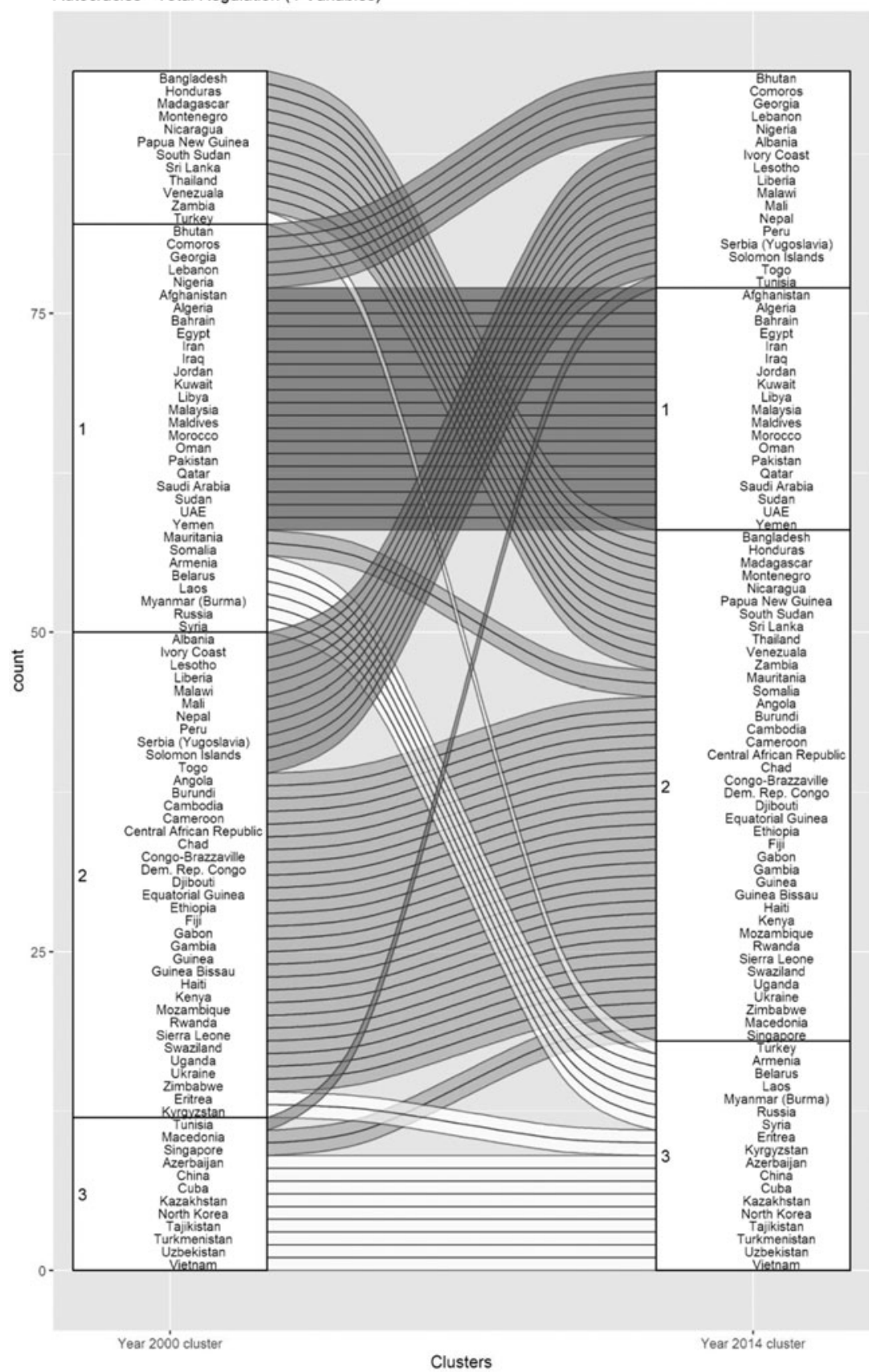

Figure 4. Change in cluster composition between 2000 and 2014, total regulation in autocracies 


\section{Change in cluster composition between 2000 and 2014}

Autocracies - Government Regulation (3-Variables)

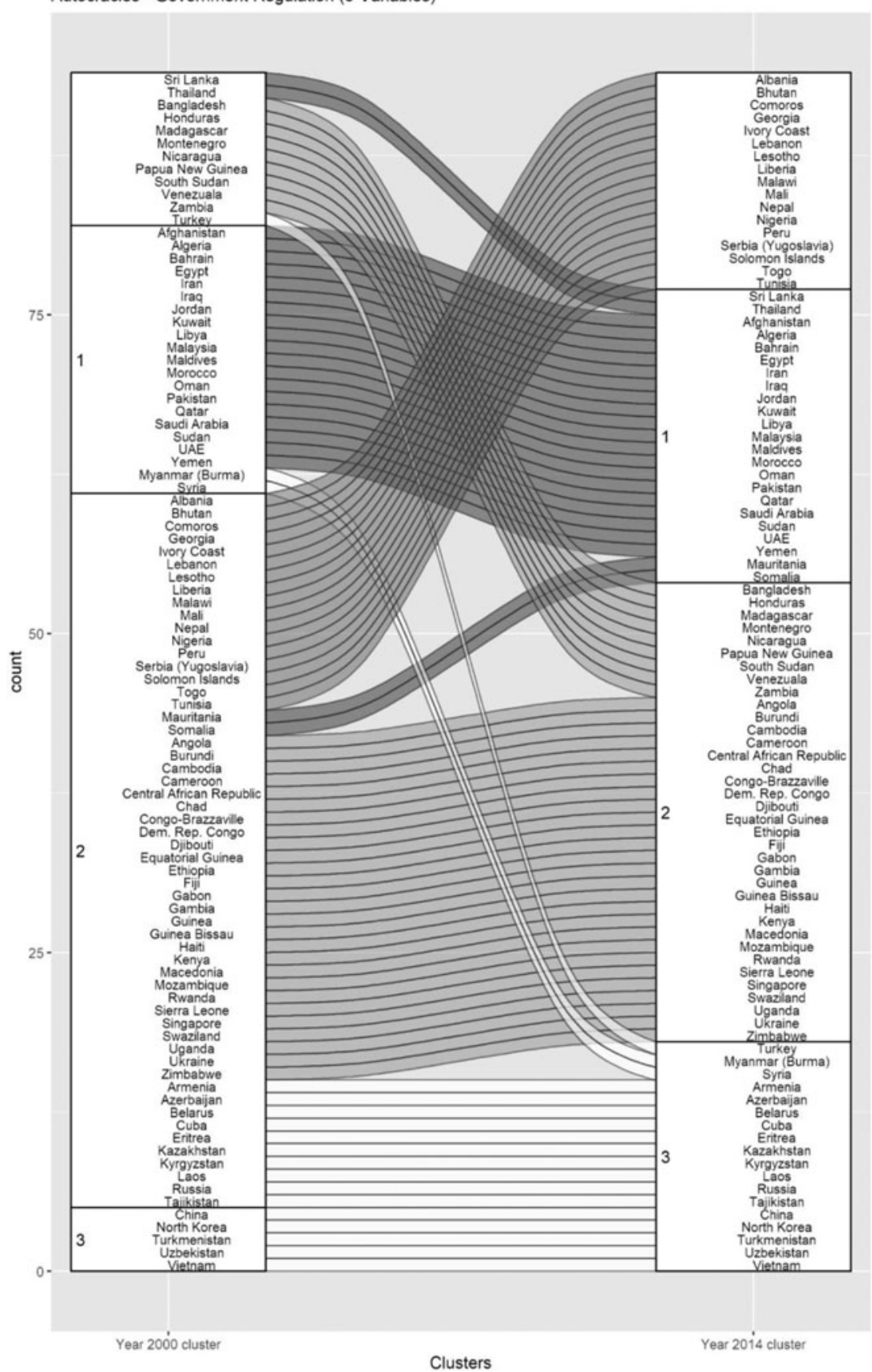

Figure 5. Change in cluster composition between 2000 and 2014, government regulation in autocracies 


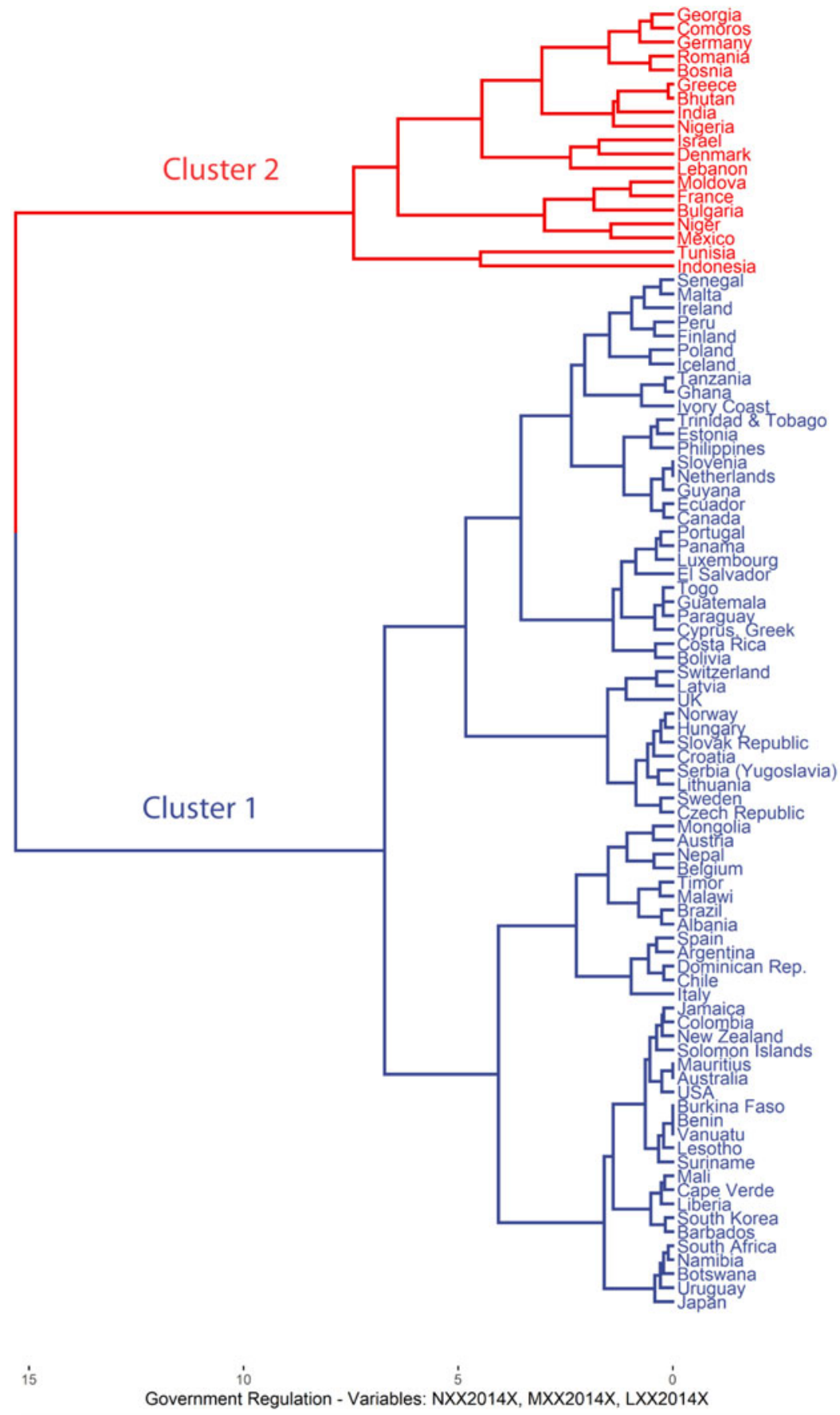

Figure 6. Dendrogram of democracies-government regulation of religion, 2014 
consequently also compatible with the theoretical frameworks, which underline these classifications. In contrast to these previous studies, however, our classification provides the empirically most rigorous findings, demonstrates that the clusters (especially in 2014) are relatively stable independently from which indicators are studied and allows us to identify countries, which are borderline cases between two clusters and thus difficult to classify. In particular, our results show that when social regulation of religion is included in the classification (which has not been done by the studies listed in Table 1), the results are still very similar. Moreover, as an addition to the previous studies, we show how the clustering of the countries changes over time, and which countries switch between clusters over the years.

When we in detail contrast our results for the four-variable solution in 2014 with the previous classifications, the following can be concluded. Firstly, when it comes to the comparison with the RAS3 data, our cluster 1 includes countries with the designation 9 (preferred religion) to 13 (religious state 1). Yet, cluster 2 includes countries with the designation 3 (separationist) to 11 (state-controlled religion, positive attitude), whereas cluster 3 includes countries with the designation 0 (specific hostility) to 9 (preferred religion). Thus, on the one hand, the RAS3 provides a more detailed classification than the one in the current study, with several overlaps with our results. On the other hand, the detailed classification in RAS3 does not always correspond to how the countries cluster when the quantity and quality of regulation is studied.

Secondly, our results are mainly in accordance with Philpott's (2019) classification, which suggests that even without knowledge about the regime's political theology, and based on the levels of regulation only, it is possible to distinguish between countries, which broadly follow the categorization of countries as religiously free, secularly repressive, and religiously repressive. Yet, as we, in comparison to Philpott, include more countries and employ more nuanced data on several indicators, our study clarifies more in detail which aspects of religion are regulated in the three clusters. Further, it is of interest to point out that five countries identified as secularly repressive by Philpott (Algeria, Egypt, Jordan, Libya, and Morocco) are in the current study consistently classified as belonging to the first cluster. This suggests that the actual levels of regulation do not always correspond to the political theology of a country.

Thirdly, clusters 1 and 3 in the current study largely overlap with Sarkissian's categories "all [groups are repressed]" and "all but one [groups are repressed]," whereas cluster 2 mainly overlaps with categories "none" or "some." Despite these broad similarities, it is also clear that if one aims to study the ways in which the different religious groups are repressed vis-à-vis each other, it is not enough to focus on the overall patterns of regulation. Thus, future classificatory efforts may find it beneficial to use the information regarding the regulation of various religious groups beyond majority and minority religions, and better incorporate it in the classifications.

Finally, our results are also similar to those of Schleutker (2021). This is interesting as she employs cluster analysis and 15 different indicators constructed from only two of the variables employed in the current study (regulation of and restrictions on the majority religion or all religions; specific types of religious support), whereas our study includes two additional indicators (discrimination against minority religions; social regulation of religion). The similarities between the current study and Schleutker's study further underline the idea that the authoritarian countries form 
Table 6. Number of indices, which support a solution with 0-10 clusters, democratic countries

\begin{tabular}{|c|c|c|c|c|c|c|c|c|c|c|c|}
\hline & 0 & 1 & 2 & 3 & 4 & 5 & 6 & 7 & 8 & 9 & 10 \\
\hline \multicolumn{12}{|l|}{2000} \\
\hline $\begin{array}{l}\text { 4-variable } \\
\text { clustering }\end{array}$ & 2 & 1 & 8 & 3 & 3 & 3 & 1 & 1 & 1 & 1 & 2 \\
\hline $\begin{array}{l}\text { 3-variable } \\
\text { clustering }\end{array}$ & 2 & 1 & 6 & 5 & 3 & 0 & 4 & 3 & 0 & 0 & 2 \\
\hline $\begin{array}{l}\text { 15-variable } \\
\text { clustering }\end{array}$ & 2 & 1 & 5 & 7 & 3 & 2 & 0 & 0 & 0 & 0 & 6 \\
\hline \multicolumn{12}{|l|}{2014} \\
\hline $\begin{array}{l}\text { 4-variable } \\
\text { clustering }\end{array}$ & 2 & 0 & 12 & 2 & 1 & 1 & 0 & 0 & 2 & 3 & 3 \\
\hline $\begin{array}{l}\text { 3-variable } \\
\text { clustering }\end{array}$ & 2 & 1 & 7 & 5 & 2 & 4 & 0 & 1 & 0 & 1 & 3 \\
\hline $\begin{array}{l}\text { 15-variable } \\
\text { clustering }\end{array}$ & 2 & 0 & 6 & 12 & 0 & 0 & 0 & 0 & 0 & 4 & 2 \\
\hline
\end{tabular}

Table 7. Average cluster silhouette widths and number of countries in each cluster, democratic countries

\begin{tabular}{|c|c|c|c|}
\hline & Cluster 1 & Cluster 2 & Cluster 3 \\
\hline \multicolumn{4}{|l|}{2000} \\
\hline 4-variable clustering & $0.57(69)$ & $0.14(16)$ & \\
\hline 3-variable clustering & $0.57(66)$ & $0.14(19)$ & \\
\hline 15 -variable clustering & $-0.06(37)$ & $0.37(46)$ & $0.27(2)$ \\
\hline \multicolumn{4}{|l|}{2014} \\
\hline 4-variable clustering & $0.57(71)$ & $0.18(22)$ & \\
\hline 3-variable clustering & $0.61(74)$ & $0.14(19)$ & \\
\hline 15 -variable clustering & $0.34(59)$ & $0.07(26)$ & $0.00(8)$ \\
\hline
\end{tabular}

three relatively robust clusters, which can be identified independently from the indicators, which are included in the clustering efforts.

\section{Results for Democratic Countries}

The results from NbClust (Tables 6 and 7) show that when the democratic countries are clustered based on the total regulation and government regulation of religion, the majority of the indices suggest that the optimal number of clusters is two. As for the 15-variable clustering, the mathematically optimal number of clusters is three. Both in 2000 and 2014, the results regarding the total level of regulation (four-variable clustering) and government regulation of religion (three-variable clustering) divide countries into those with low and high levels of regulation. As is the case for authoritarian countries, when the social 
regulation of religion is excluded from the clustering, the clustering changes less in 2014 than in 2000. Regarding the clustering based on the 15 sub-categories of regulation, these results are somewhat difficult to interpret, as at least one of the clusters in both years has a dissatisfactory clustering structure. Again, the below description of the findings focuses on year 2014 and on the changes between 2000 and 2014, whereas the detailed results for year 2000 can be found in the online Appendix.

\section{Results for 2014}

When we study the total level of regulation, the two-cluster solution divides countries into those with low and high levels of regulation (Figure 7). In the first cluster, we find as many as 71 countries, located in different parts of the world. The average values of regulation in this cluster are low, even though the mean of support for religion is somewhat higher than the mean value for the other regulatory categories (Figure 8a). In contrast, in the second cluster, we find 22 countries, which likewise are located in different parts of the world. The countries in this cluster have, on average, high levels of regulation, particularly when it comes to support for religion and social regulation of religion. Finally, the silhouette analysis shows that cluster 1 has a good internal coherence. The cohesion among the second cluster is low, and as many as four countries (Czech Republic, Mexico, Poland, Sweden) experience negative silhouette widths.

The results from the clustering based on government regulation of religion (Figure 6) are very similar to the above discussed results. Indeed, only five countries cluster differently, namely Czech Republic, Poland, Sweden, and the UK (now in cluster 1 ) and Niger (now in cluster 2). The cluster coherence in cluster 1 is good, but low in cluster 2, where five countries also have negative silhouette widths (Bosnia, France, Lebanon, Mexico, and Niger).

When the countries are clustered based on the 15 sub-categories of regulation, three different clusters of countries can be distinguished (see Appendix Figure A.13). In the first cluster, we find as many as 59 countries and the silhouette analysis suggests a satisfactory coherence among the countries. The mean levels of regulation regarding discrimination as well as the restrictions on majority religion/all religions are low, whereas the average levels of religious support are relatively high for several categories. Most notably, the countries in this cluster support religion in the form of laws on relationships, sex, and reproduction, funding of religion as well as other forms of support for religion.

The second cluster consists of 26 countries, which are mainly located in Europe. The clustering structure is weak, and six countries have negative silhouette widths. Finally, in the third cluster, we find only eight countries (Bhutan, Comoros, India, Indonesia, Israel, Lebanon, Nigeria, Tunisia). Even though these countries cluster together, the cohesion of the cluster is poor and five of the countries have negative silhouette widths. Given the weak cluster structure in clusters 2 and 3, it is not appropriate to interpret the cluster mean values as they are shown in Figure A.14.

\section{Comparison Between 2000 and 2014}

The two-cluster solutions are helpful as they clearly demonstrate that a large majority of the democratic countries have relatively low levels of regulation, and that only a 


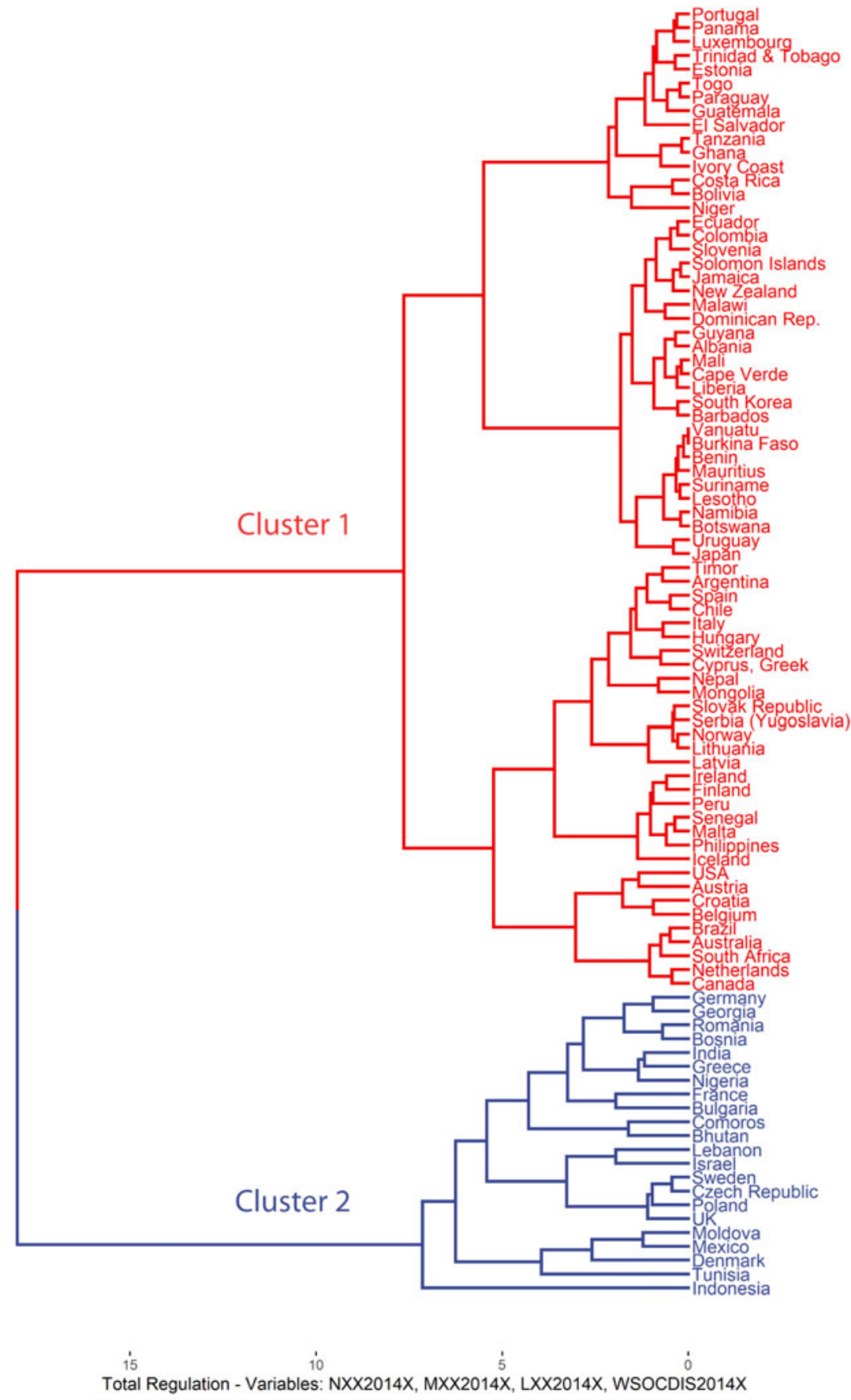

Figure 7. Dendrogram of democracies-total regulation, 2014 


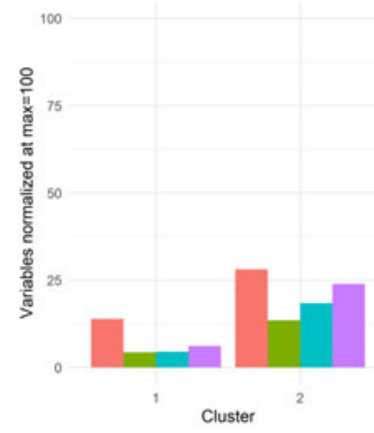

(a)

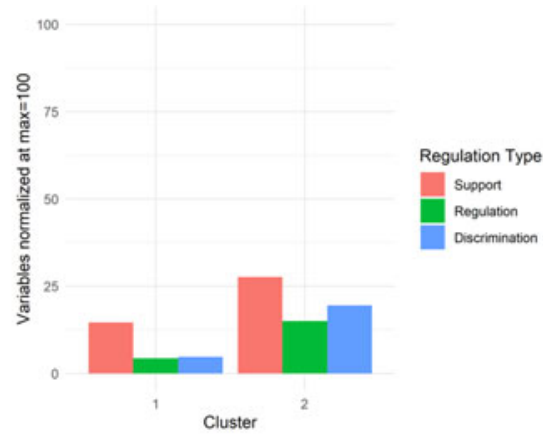

(b)

Figure 8. Cluster mean levels of regulation in 2014: total level of regulation and government regulation of religion. (a) Average level of total regulation. (b) Average level of government regulation

minority of the countries impose high levels of regulation on religion. In addition, the results suggest that there are no clear patterns of regulation among the countries in the second cluster, but that they are joined in the same cluster as they experience high levels of regulation at least in one regulatory category. It is further of interest that based on the visual inspection of the figures, it is difficult to find any clear patterns regarding how the countries cluster, for example, when it comes to geographical location, majority religion, political history of communism, or democratic longevity. Yet, it is also important to emphasize that if, in addition to these more general patterns, the more detailed patterns among the democratic countries would be of interest, it is possible to study the sub-cluster structure.

As for the changes in the classification of the countries between 2000 and 2014, the study of the Sankey diagram for the total level of regulation (Figure 9) shows that both clusters are relatively stable. As many as 58 countries belong to the first cluster both in 2000 and 2014, whereas 12 countries belong to cluster 2 in both years. Four countries (Czech Republic, Mexico, Poland, and the UK) switch from cluster 1 to cluster 2 by 2014, and Croatia switches from cluster 2 to cluster 1 . All other changes in the structure of the clusters are related to the countries, which either became democratic or autocratic by 2014 and thus joined or exited one of the clusters. As for the government regulation of religion (Figure 10), the results are again relatively similar. However, there is somewhat more fluctuation between the two clusters, which also means that the number of countries, which are found in cluster 2 in both years, is somewhat smaller. In other words, exclusion of social regulation reduces the size of the cluster with countries with high levels of regulation.

\section{Comparison to Previous Research}

A comparison of our results with the quantitative studies listed in Table 2 shows that by dividing the countries into two main clusters (with the second cluster having a low cluster coherence), our results are more general than the results obtained by Madeley (2009) and Fox (2019). Indeed, the argument could be made that a classification, which places countries either in low-regulation or high-regulation cluster, adds 
Change in cluster composition between 2000 and 2014

Democracies - Total Regulation (4-Variables)

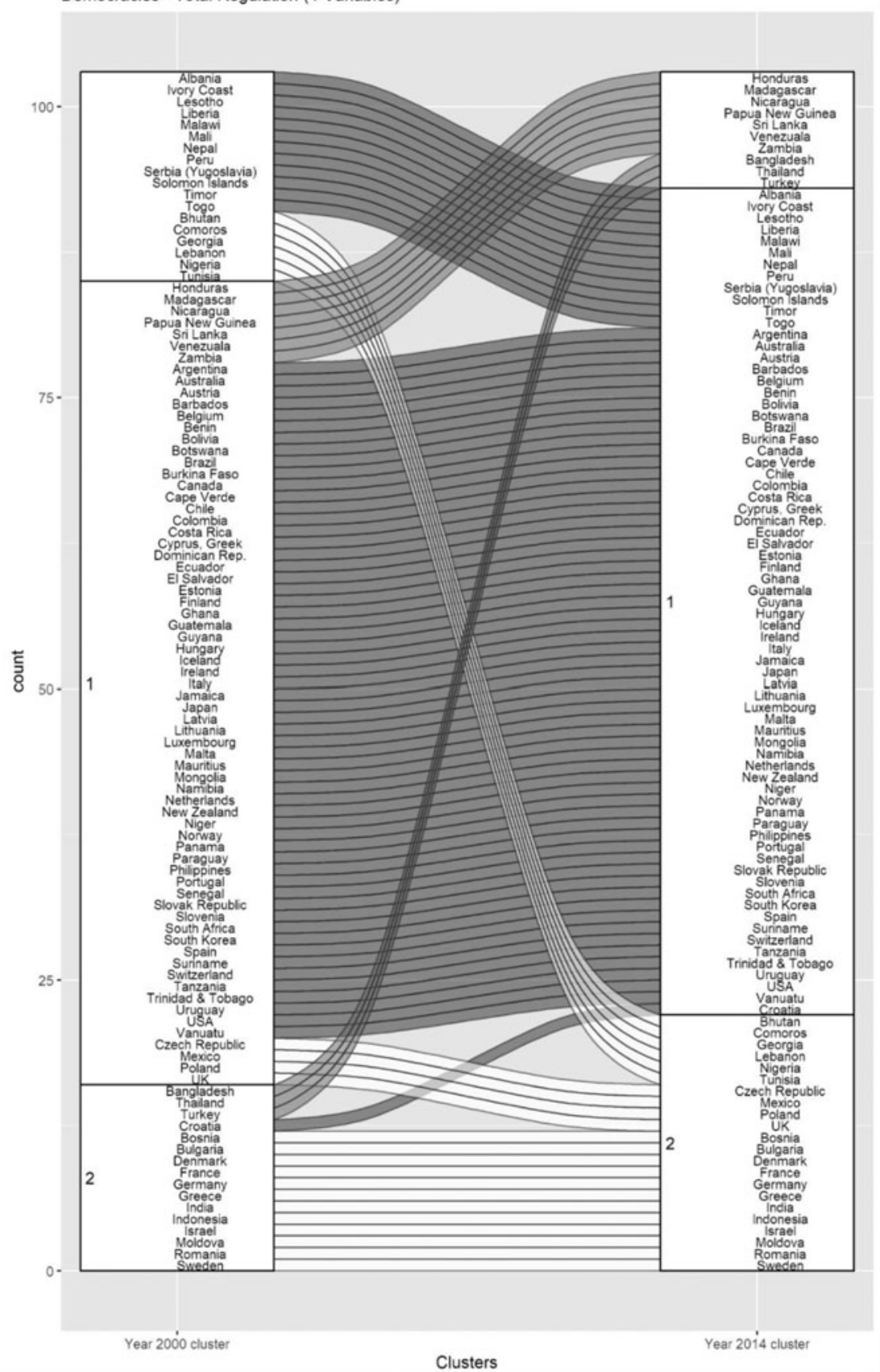

Figure 9. Change in cluster composition between 2000 and 2014, total regulation in democracies 
Change in cluster composition between 2000 and 2014

Democracies - Government Regulation (3-Variables)

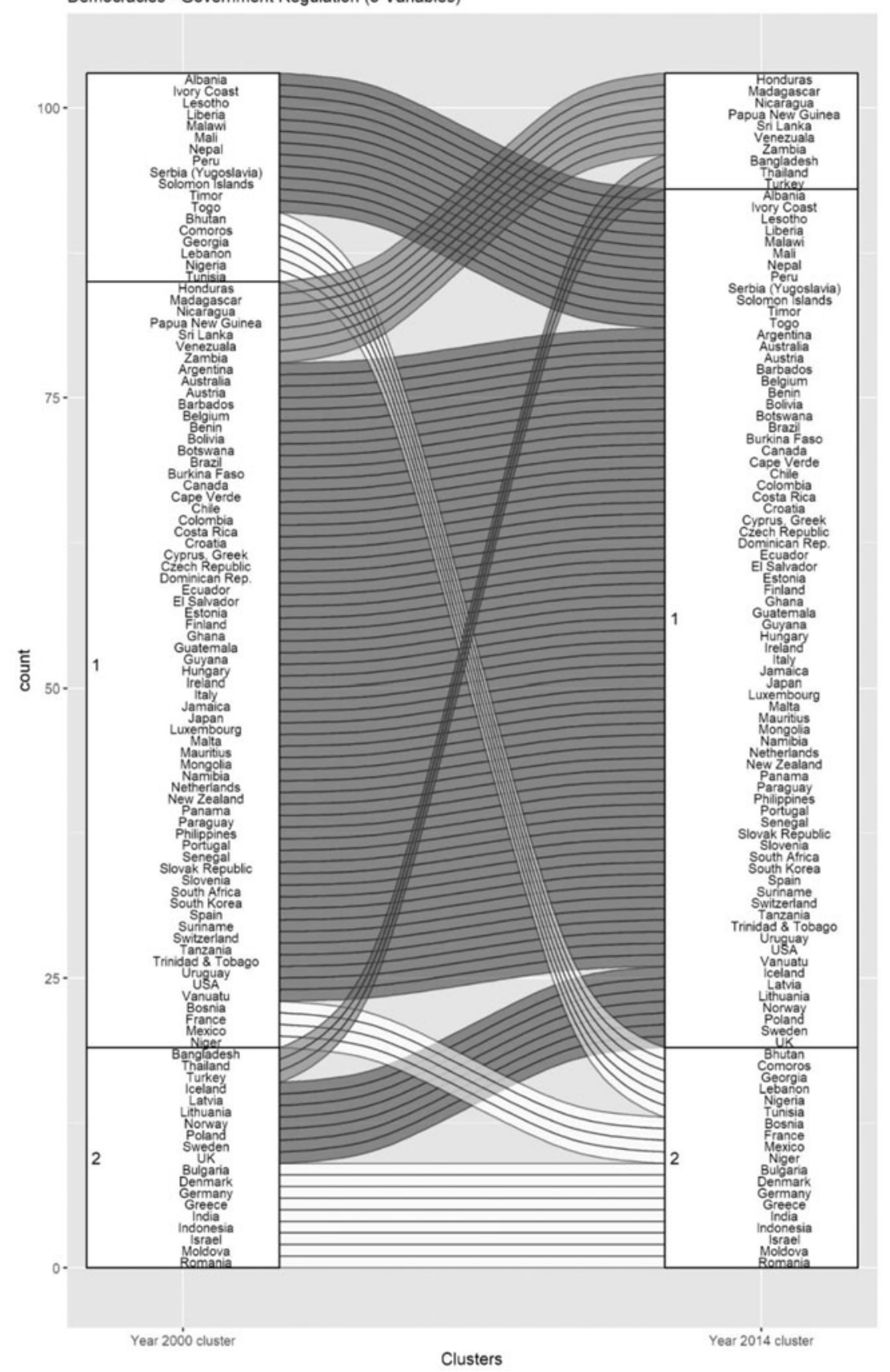

Figure 10. Change in cluster composition between 2000 and 2014, government regulation in democracies 
very little to our understanding of the cross-country differences regarding the regulation of religion. Our method, however, allows for a detailed look at the structure inside of clusters as well and provides thus many interesting observations regarding the results of previous qualitative studies.

We see the following benefits with the exercise: Firstly, by focusing on the study of all democratic countries, rather than on regulation in particular regions only, the classification clarifies the fact that a large majority of democratic countries-independently from their geographical location, majority religion affiliation, or GDP/capita-have low levels of regulation. Thus, democratic countries, which have elevated levels of regulation, are exceptions. This information can be utilized for the purposes of case selection in qualitative studies. For example, it would be interesting to understand why two democratic countries, which do not have much in common when it comes to geographical, political, sociological, and economic factors, nevertheless share low levels of regulation. Similarly, it is important to know that findings for any of the countries in the high-regulation cluster may not be generalizable to other democratic countries.

Secondly, the study of changes over time may prove to be valuable when it comes to understanding the determinants of regulation. In particular, this applies to the information regarding the countries that were authoritarian in 2000, but became democratic by 2014. Interestingly, a large majority of these countries had low levels of regulation even when they were autocratic. Thus, low levels of regulation in these countries do not appear to be related to the democratic regiment, but rather to some mechanisms of institutional path dependence. This also means that the reasons for the low levels of regulation in these newly democratized countries are different than in countries, which have been democratic for a long time and where the levels of regulation have declined over the years. Such differences in the pathways to low levels of regulation in the currently democratic countries should be taken into consideration when it comes to the selection of independent variables in quantitative studies on the determinants of regulation.

Thirdly, the comparison between our results and qualitative studies regarding the relationship between state and religion (Table 2) is instructive. To start with, we notice that the classification by Kuru (2007) between assertive and passive secularism is helpful, given that the country with passive secularism (USA) exclusively belongs to the cluster where the levels of regulation are low. The two assertively secular countries (France, Turkey), in turn, for the most part classify with the countries where the levels of regulation are higher. This gives support to the idea that the different types of state ideologies toward religion also influence the levels of regulatory practices. The comparison to Buckley (2017), who distinguishes benevolent secularism as a third category of secularism, is providing further insights. All three countries, which are classified as benevolent secularism by Buckley (Ireland, Senegal, Philippines), often cluster together in a common sub-cluster with Finland, Malta, Peru, and Iceland. All these countries share many similarities in how they regulate religion. They also are relatively close to the sub-cluster containing the USA. Thus, the clustering of the countries suggests that even fundamental differences in the state ideology regarding passive and benevolent secularism do not necessarily transform into large differences in regulation of religion. Or to put it differently, there seems to be 
(at least) two roads to low levels of regulation in democratic countries, namely the passive and the benevolent pathway.

Further, as for the three categories of nationalism put forward by Soper and Fetzer (2018), there is some support to the idea that in those cases where nationalism and religion are intertwined (Greece), even the levels of regulation are higher. At the same time, it is clear that the distinction between secular nationalism and civil-religious nationalism are poor predictors for the actual level of regulation measured by RAS3 data. Indeed, while Uruguay (secular nationalism) and the USA (civil-religious nationalism) cluster together with the countries with low levels of regulation, India (secular nationalism) and Israel (civil religious nationalism) cluster together in the group of countries with high levels of regulation. Thus, the indication if a country is promoting secular nationalism or civil religious nationalism seems to be less helpful in understanding the way in which the countries cluster, whereas the distinction between different types of secularism (see the discussion above) seems to be more fruitful. To put it differently, roads to high levels of regulation in democratic countries can go through both the political ideologies of (assertive) secularism and religious nationalism.

Finally, it is of interest to return to the observations by Driessen (2014), who aims to clarify how democracies can satisfy Stepan's (2000) requirement of twin toleration between state and church, and at the same time be religiously friendly. Driessen's argument is that high levels of regulation on religion do not fulfill the requirement of twin toleration, whereas high levels of government favoritism do not need to be problematic from the democratic point of view. Against this background, it is of interest that the mean levels of support for religion are higher in the two democratic clusters in comparison to the mean levels of other types of regulation. These observations give support to the idea that relatively high levels of government favoritism and democracy do co-exist. Moreover, the mean levels of negative restrictions on religion in the first, "low-regulation" cluster are very low, which indicates that many democratic countries are, if we were to judge based on the levels of regulation only, in essence religiously friendly democracies. However, the fact that the mean levels of negative regulation in the "high-regulation" cluster are somewhat elevated (even though the mean values need to be interpreted with extreme caution due to the poor cluster coherence), suggests that at least some countries in the second cluster may be at risk of violating against the principle of twin tolerations.

\section{Concluding Remarks}

Our paper makes three important contributions. Firstly, the paper makes a methodological contribution, in that we demonstrate that numerical classifications can be fruitful when it comes to understanding cross-country differences and similarities in the regulation of religion. In particular, we show that it is possible to identify groups of countries, which cluster consistently, with different indicators included in the cluster analysis. Here we refer especially to the results for the authoritarian countries. Thus, we would encourage researchers who work with more theoretically based classifications to try out cluster analysis to explore if and how the clustering of the countries changes in case a particular theoretical dimension is included or excluded. 
Secondly, by classifying the countries, we describe the broad cross-country similarities and differences over time, and also shed light on the countries which are difficult to classify and thus can be considered as outliers. Moreover, our study investigates how the countries, which switched regime type between the years, classify. Due to the employed method, our results are more empirically robust than the results of previous classification efforts, which often have relied on fewer indicators and the author's considerations regarding the cut-off points between the different groups of countries. As our paper, however, is the first one to apply cluster analysis to the classification of a larger set of countries regarding the regulation of religion, it needs to be considered as exploratory. Future studies should investigate if and how the results would be different in case other datasets on regulation are employed.

Thirdly, by comparing our results with previous quantitative and qualitative work on state-religion relationships, we discuss many interesting similarities and differences. The comparison with the previous research on authoritarian regimes shows that there are many overlaps between our results and previous classifications, which further give support to the idea that three relatively stable clusters of authoritarian regulation of religion can be identified. Our results add to this previous work by employing empirically robust numerical classification methods, testing how the inclusion/exclusion of certain variables from the classification influences the results and by studying the changes in the classification of countries over time.

The comparison of our results with previous work on democratic countries, in turn, shows that the clustering separates between the countries of passive secularism (low levels of regulation) and assertive secularism (high levels of regulation). Moreover, countries, which have been identified as promoting benevolent secularism, often cluster closely to each other. Further, in countries where religion is mixed with nationalism, the levels of regulation tend to be higher, whereas secular nationalism and civil-religious nationalism are poor predictors of the clustering of the countries. Finally, given that a large majority of the democratic countries have low levels of regulation, and that the levels of supportive policies are in general higher than the levels of negative restrictions, the results indicate that a large majority of the democratic countries are, at least to a certain extent, religiously friendly.

The findings of the current study can be employed in future research in various ways. We do not suggest that numerical classifications should replace theoretical considerations regarding the classification of the countries, but rather hope-as already discussed above-that our research sparks an interest in the application of cluster analysis among researchers who develop theoretically based classifications or/and who work with other datasets on the regulation of religion. Further, our results are informative as they identify countries, which are similar (countries, which belong to the same category) and different (countries, which belong to different categories), difficult to classify (borderline cases between two clusters; countries, which are classified differently in previous studies), and countries which cluster differently over time. This information can be employed for the purposes of qualitative studies when case selection is made, for example, based on the logic of "the most similar systems design" versus "the most different systems design" (e.g., Landman 2008: 29ff). Similarly, our classification should be helpful when it comes to the contextualization of previous case studies. Regarding quantitative studies, the classification of 
authoritarian regimes can be employed as dependent and independent variables when the aim is to understand the determinants and consequences of cross-country similarities and differences. Concerning democratic countries, the clustering of the countries into two clusters suggests that there are several roads to low (and high) levels of regulation, which cannot easily be detected with the help of cross-sectional regression analysis.

Supplementary material. The supplementary material for this article can be found at https://doi.org/10. 1017/S175504832100033X.

Data Availability Statement. Additional results for this article are available in the online Appendix. Moreover, the replication data for the paper are available on the Harvard Dataverse at: https:/doi.org/ 10.7910/DVN/C9D028

\section{References}

Arts W and Gelissen J (2002) Three Worlds of Welfare Capitalism or More? A State-of-the-Art Report. Journal of European Social Policy 12(2), 137-158.

Ben-Nun Bloom P (2015) State-Level Restriction of Religious Freedom and Women's Rights: A Global Analysis. Political Studies 64(4), 832-853.

Brown D (2019) Measuring Long-Term Patterns of Political Secularization and Desecularization: Did They Happen or Not? Journal for the Scientific Study of Religion 58(3), 570-590.

Buckley DT (2017) Faithful to Secularism The Religious Politics of Democracy in Ireland, Senegal and the Philippines. New York: Columbia University Press.

Buckley DT and Mantilla LF (2013) God and Governance: Development, State Capacity, and the Regulation of Religion. Journal for the Scientific Study of Religion 52(2), 328-348.

Charrad M, Ghazzali N, Boiteau V and Niknafs A (2014) NbClust: An R Package for Determining the Relevant Number of Clusters in a Data Set. Journal of Statistical Software 61(6), 1-36.

Coppedge M, Gerring J, Henrik Knutsen C, Lindberg SI, Teorell J, Altman D, Bernhard M, Fish MS, Glynn A, Hicken A, Luhrmann A, Marquardt KL, McMann K, Paxton P, Pemstein D, Seim B, Sigman R, Skaaning S-E, Staton J, Wilson S, Cornell A, Alizada N, Gastaldi L, Gjerløw H, Hindle G, Ilchenko N, Maxwell L, Mechkova V, Medzihorsky J, von Römer J, Sundström A, Tzelgov E, Wang Y-t, Wig T and Ziblatt D (2020) "V-Dem [Country-Year/Country-Date] Dataset v10". Varieties of Democracy (V-Dem) Project. Available at https://doi.org/10.23696/vdemds20.

Dahl RA (1989) Democracy and Its Critics. New Haven and London: Yale University Press.

Driessen MD (2014) Religion and Democratization Framing Religious and Political Identities in Muslim and Catholic Countries. New York, NY: Oxford University Press.

Duit A (2016) The Four Faces of the Environmental State: Environmental Governance Regimes in 28 Countries. Environmental Politics 25(1), 69-91.

Elkins Z (2000) Gradations of Democracy? Empirical Tests of Alternative Conceptualizations. American Journal of Political Science 44(2), 293-300.

Everitt BS, Landau S, Leese M and Stahl D (2011) Cluster Analysis. West Sussex: John Wiley \& Sons Ltd.

Finke R and Martin RR (2014) Ensuring Liberties: Understanding State Restrictions on Religious Freedoms. Journal for the Scientific Study of Religion 53(4), 687-705.

Finke R, Martin RR and Fox J (2017) Explaining Discrimination against Religious Minorities. Politics and Religion 10(2), 389-416.

Fox J (2006) World Separation of Religion and State into the 21st Century. Comparative Political Studies 39, $537-569$.

Fox J (2008) A World Survey of Religion and the State. Cambridge: Cambridge University Press.

Fox J (2013) An Introduction to Religion and Politics Theory and Practice. London and New York: Routledge.

Fox J (2014) Is it Really God's Century? An Evaluation of Religious Support and Discrimination from 1990 to 2008. Politics and Religion 7, 4-27.

Fox J (2019) The Religion and State Project, Main Dataset and Societal Module, Round 3. 
Fox J (2020) Thou Shalt Have No Other Gods Before Me. Why Governments Discriminate Against Minorities. Cambridge: Cambridge University Press.

Fox J, Finke R and Eisenstein MA (2019) Examining the Causes of Government-Based Discrimination Against Religious Minorities in Western Democracies: Societal-Level Discrimination and Securitization. Comparative European Politics 17, 885-909.

Gill A (1998) Rendering Unto Caesar: The Catholic Church and the State in Latin America. Chicago: University of Chicago Press.

Gill A (2007) The Political Origins of Religious Liberty. Cambridge: Cambridge University Press.

Gorski PS and Altinordu A (2008) After Secularization?. Annual Review of Sociology 34, 55-85.

Green TH (2010) The Resistance to Minarets in Europe. Journal of Church and State 52(4), 619-643.

Grim BJ and Finke R (2006) International Religion Indexes: Government Regulation, Government Favoritism, and Social Regulation of Religion. Interdisciplinary Journal of Research on Religion 2, Article 1.

Grim BJ and Finke R (2007) Religious Persecution in Cross-National Context: Clashing Civilizations or Regulated Religious Economies? American Sociological Review 72, 633-658.

Grzymala-Busse A (2016) Weapons of the Meek: How Churches Influence Public Policy. World Politics 68 (1), 1-36.

Humanists International (2020) Humanists at Risk: Action Report 2020.

Huntington SP (1993) The Clash of Civilizations? Foreign Affairs 72, 22-49.

Kassambara A and Mundt F(2017) factoextra: Extract and Visualize the Results of Multivariate Data Analyses. R package version 1.0.5. Available at https://CRAN.R-project.org/package=factoextra.

Kattler A and Ettensperger F (2020) National Internal Security Policies Across Europe-A Comparative Analysis Applying Big Data Clustering Techniques. Political Research Exchange 2(1), 1787796.

Knill C and Preidel C (2015) Institutional Opportunity Structures and the Catholic Church: Explaining Variation in the Regulation of Same-Sex Partnerships in Ireland and Italy. Journal of European Public Policy 22(3), 374-390.

Kuru AT (2007) Passive and Assertive Secularism Historical Conditions, Ideological Struggles, and State Policies toward Religion. World Politics 59, 568-594.

Landman T (2008) Issues and Methods in Comparative Politics: An Introduction. London and New York: Routledge.

Le S, Josse J and Husson F (2008) FactoMineR: An R Package for Multivariate Analysis. Journal of Statistical Software 25(1), 1-18.

Lindekilde L, Mouritsen P and Zapata-Barrero R (2009) The Muhammed Cartoons Controversy in Comparative Perspective. Ethnicities 9(3), 291-313.

Lührmann A, Tannenberg $\mathbf{M}$ and Lindberg SI (2018) Regimes of the World (RoW): Opening New Avenues for the Comparative Study of Political Regimes. Politics and Governance 6(1), 60-77.

Madeley JTS (2009) Unequally Yoked: The Antinomies of Church-State Separation in Europe and the USA. European Political Science 8, 273-288.

Mataic DR (2018) Countries Mimicking Neighbors: The Spatial Diffusion of Governmental Restrictions on Religion. Journal for the Scientific Study of Religion 57(2), 221-237.

Norris P and Inglehart R (2004) Sacred and Secular: Religion and Politics Worldwide. New York: Cambridge University Press.

Obinger H and Wagschal U (2001) Families of Nations and Public Policy. West European Politics 24(1), 99-114.

Pew Research Center (2009) Global Restrictions on Religion.

Pew Research Center (2019) A Closer Look at How Religious Restrictions Have Risen Around the World.

Philpott D (2019). Religious Freedom in Islam. The Fate of a Universal Human Right in the Muslim World Today. Oxford: Oxford University Press.

Philpott D and Shah TS (2018) (eds) Under Caesar's Sword How Christians Respond to Persecution. Cambridge: Cambridge University Press.

Rousseeuw PJ (1987) Silhouettes: A Graphical Aid to the Interpretation and Validation of Cluster Analysis. Journal of Computational and Applied Mathematics 20, 53-65.

Sarkissian A (2009) Religious Reestablishment in Post-Communist Polities. Journal of Church and State 51 (3), 472-501. 
Sarkissian A (2015) The Varieties of Religious Repression Why Governments Restrict Religion. Oxford: Oxford University Press.

Schleutker E (2019) Discrimination Against Religious Minorities. Journal of Church and State 61(2), 282-307.

Schleutker E (2021) Co-optation and Repression of Religion in Authoritarian Regimes. Politics and Religion 14, 209-240.

Soper JC and Fetzer JS (2007) Religious Institutions, Church-State History and Muslim Mobilisation in Britain, France and Germany. Journal of Ethnic and Migration Studies 33, 933-944.

Soper JC and Fetzer JS (2018) Religion and Nationalism in Global Perspective. Cambridge: Cambridge University Press.

Stark R and Iannaccone LR (1994) A Supply-Side Reinterpretation of the "Secularization" of Europe. Journal for the Scientific Study of Religion 33, 230-252.

Stensvold A (2020) (ed.) Blasphemies Compared Transgressive Speech in a Globalised World. London: Routledge.

Stepan AC (2000) Religion, Democracy, and the "Twin Tolerations". Journal of Democracy 11(4), 37-57.

Teorell J, Coppedge M, Lindberg S, and Skaaning S-E (2019) Measuring Polyarchy Across the Globe, 1900-2017. Studies in Comparative International Development 54, 71-95.

United Nations (2020) List of Member States. Available at https://www.un.org/en/member-states/. Accessed in: 26.20.2020.

Felix Ettensperger is a research associate and political science lecturer at Albert-Ludwigs-Universität in Freiburg (Germany). His research interests are comparative politics, conflict research, and advanced statistical methods. He currently holds the position as Assistant Managing Editor of the academic journal Statistics, Politics and Policy.

Elina Schleutker has a PhD in Political Science from the University of Heidelberg (Germany). She currently works at the University of Freiburg (Germany). Her research focuses on religion, authoritarianism, and comparative politics.

Cite this article: Ettensperger F, Schleutker E (2022). Identification of Cross-Country Similarities and Differences in Regulation of Religion Between 2000 and 2014 with Help of Cluster Analysis. Politics and Religion 15, 526-558. https://doi.org/10.1017/S175504832100033X 